Military Technical College Kobry El-Kobbah, Cairo, Egypt

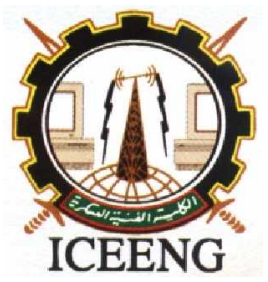

\author{
$6^{\text {th }}$ International Conference \\ on Electrical Engineering \\ ICEENG 2008
}

\title{
Grid synchronization of brushless doubly fed asynchronous generators in wind power systems
}

\author{
By \\ Renato Carlson* \\ Helio Voltolini**
}

\section{Abstract:}

The vector control of the Brushless Doubly Fed Induction Generator (BDFIG) was implemented in Matlab/Simulink/SymPowerSystems using a rotating reference frame fixed on the power winding flux. The control algorithms of the grid-side and controlside converters can regulate the active and reactive power independently. The measure of the power winding flux angle, realized using a PLL, showed good performance during the system startup and has demonstrated a robust behavior under noisy voltage and current signals. A synchronization strategy is proposed that acts on the control-side converter current control loops to ensure the conditions for a smooth connection. Soft and fast synchronization is achieved at the minimum rotating speed. To validate the simulated results an experimental setup with a Doubly Fed Induction Generator with brushes was tested with the same control strategy and the experimental results showed coherent with the simulated ones.

\section{Keywords:}

Brushless, induction generator and synchronization.

* Federal University of Santa Catarina, Florianopolis, Brazil

** Federal Technical University of Parana, Ponta Grossa, Brazil 


\section{Introduction:}

Doubly-fed induction generators (DFIG) with a wound rotor are used as variable speed electric generator especially in wind power generators systems [1]. This type of generator is controlled by power converters with reduced power rating when compared with the machine electrical power output. The stator winding is connected to the electrical grid and the rotor winding is connected to a bi-directional static power converter through slip-rings. The presence of slip rings reduces the lifetime of the machine and increases the maintenance costs.

An alternative to overcome this drawback is the brushless doubly-fed induction generator (BDFIG) [2,3]. The BDFIG has its origins in the technology of cascade induction machines and consists of two three-phase windings with different number of pairs of poles in the stator and a special rotor cage. The stator power and control windings are connected to the three phase power grid; the power winding is connected directly while the control winding is connected through a bi-directional static power converter. A simplified block-diagram of the BDFIG complete system is presented on Fig. 1.

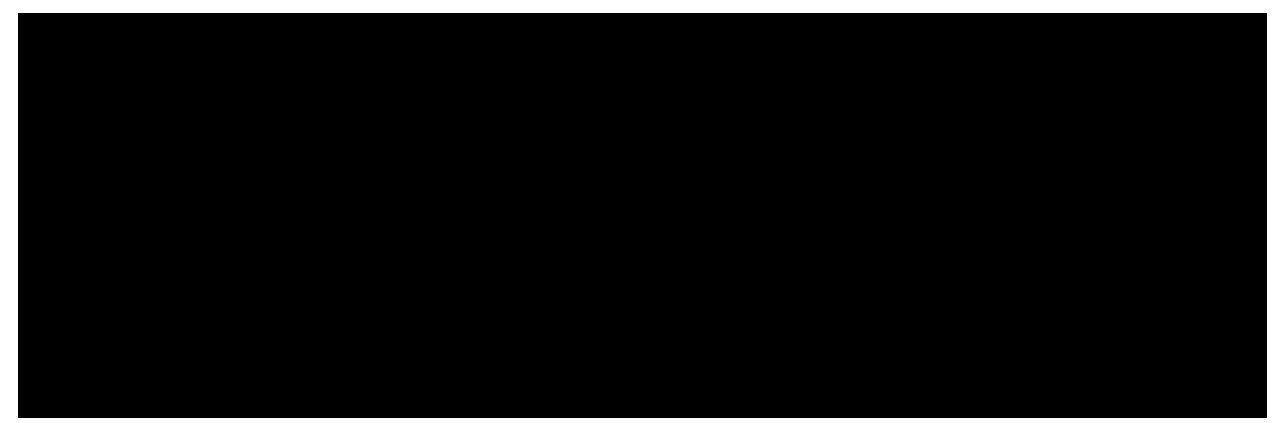

Fig. (1): Representation of the power flow in the system using a 'motor' convention.

Very few references exist on the synchronization process of doubly-fed induction generators [4-7] and none concerning the BDFIG. A method to synchronize the BDFIG to the grid is presented here that exploits the large capacity of the microprocessors that already control the PWM converters.

This paper presents an analysis of the BDFIG's vector control based on simulated results with Matlab/Simulink/SymPowerSystem. Dynamic results of the control algorithm and grid synchronization process are presented.

\section{The grid-side converter:}

The grid-side PWM voltage fed converter is connected to the grid through three singlephase chokes. With this configuration it is possible to operate using boost mode and have attractive features as constant DC bus voltage, low harmonic distortion of grid current, 
bidirectional power flow and adjustable power factor. The main objective of the grid-side converter is to keep the DC-link voltage constant regardless the magnitude and direction of the control winding power. The grid-side converter control, shown in Fig. 2, is based on the dq voltage equations of the grid-reactance-converter system expressed as:

$$
\left.\begin{array}{l}
\mathrm{v}_{\mathrm{qe}}=\mathrm{Ri}_{\mathrm{qe}}+\mathrm{L} \frac{\mathrm{di}_{\mathrm{qe}}}{\mathrm{dt}}+\omega_{\mathrm{e}} \mathrm{Li}_{\mathrm{de}}+\mathrm{v}_{\mathrm{q} 1} \\
\mathrm{v}_{\mathrm{de}}=\mathrm{Ri}_{\mathrm{de}}+\mathrm{L} \frac{\mathrm{di} \mathrm{de}_{\mathrm{de}}}{\mathrm{dt}}-\omega_{\mathrm{e}} \mathrm{Li}_{\mathrm{qe}}+\mathrm{v}_{\mathrm{d} 1}
\end{array}\right\}
$$

where $\mathrm{L}$ and $\mathrm{R}$ are the inductance and resistance of the chokes, respectively, $\mathrm{v}_{\mathrm{qe}}, \mathrm{v}_{\mathrm{de}}, \mathrm{i}_{\mathrm{qe}}$, $\mathrm{i}_{\mathrm{de}}$ are the electrical grid voltages and currents, $\mathrm{v}_{\mathrm{q} 1}$ and $\mathrm{v}_{\mathrm{d} 1}$ are the $\mathrm{AC}$ side voltages of the converter all in the dq reference frame and $\omega_{\mathrm{e}}$ is the angular frequency of the electrical grid. The vector control approach is used, with a reference frame oriented along the grid voltage vector $\left(\mathrm{V}_{\mathrm{e}}\right)$ position, such that $\mathrm{v}_{\mathrm{de}}=\mathrm{V}_{\mathrm{e}}$ and $\mathrm{v}_{\mathrm{qe}}=0$. This allows independent control of the active and reactive power through $i_{\mathrm{de}}$ and $\mathrm{i}_{\mathrm{qe}}$, respectively according to following equations:

$$
\left.\begin{array}{l}
\mathrm{P}_{\mathrm{e}}=\frac{3}{2} \mathrm{~V}_{\mathrm{e}} \mathrm{i}_{\mathrm{de}} \\
\mathrm{Q}_{\mathrm{e}}=-\frac{3}{2} \mathrm{~V}_{\mathrm{e}} \mathrm{i}_{\mathrm{qe}}
\end{array}\right\}
$$

The DC link voltage can be controlled for the active power flow between the two converters above the peak value of the grid voltage. Fig. 2 shows the scheme of the gridside converter and its controls as simulated in Matlab/Simulink/SimPower Systems.

\section{The control-side converter:}

The vector control of the control-side converter is represented in block diagram in Fig. 3. The control of the reactive power is realized by acting over the control winding current $\mathrm{i}_{\mathrm{dc}}$. The reference current is given by a PI controller that adjusts the reactive power to a desired amount (e.g. $\mathrm{Q}_{\mathrm{p}}{ }^{*}$ ). Similarly, the control of the active power is realized by acting over the control winding current $\mathrm{i}_{\mathrm{qc}}$. There are three possible situations for defining the current reference in this case. Two of them require a PI controller and correspond to the two speed limits: the maximum and minimum rotating speed. The third one corresponds to track the maximum turbine power for each wind speed. 


\section{Power winding flux estimation:}

The aim of the control-side converter is to impose a current to the control winding and to control independently the active and reactive power in the power winding.

After the acquisition, the power winding abc voltages and currents are transformed into a stationary $\alpha \beta$ coordinate system. The axis $\alpha$ is aligned with the line-to-neutral voltage $\mathrm{V}_{\text {an. }}$. Then, the $\alpha \beta$ power winding voltages and currents are calculated as:

$$
\left.\begin{array}{l}
\mathrm{V}_{\alpha \mathrm{p}}=\frac{1}{3}\left(\mathrm{~V}_{\mathrm{abp}}-\mathrm{V}_{\text {cap }}\right) \\
\mathrm{V}_{\beta \mathrm{p}}=-\frac{1}{\sqrt{3}}\left(\mathrm{~V}_{\mathrm{abp}}+\mathrm{V}_{\text {cap }}\right)
\end{array}\right\}
$$

The power winding flux is calculated in the stationary $\alpha \beta$ and rotating $\mathrm{dq}$ axes as:

$$
\begin{aligned}
& \left.\begin{array}{l}
\lambda_{\alpha p}=\int\left(V_{\alpha p}-r_{p} i_{\alpha p}\right) d t \\
\lambda_{\beta p}=\int\left(V_{\beta p}-r_{p} i_{\beta p}\right) d t
\end{array}\right\} \\
& \left.\begin{array}{l}
\lambda_{d p}=\lambda_{\alpha p} \cos \left(\theta_{p}\right)+\lambda_{\beta p} \sin \left(\theta_{p}\right) \\
\lambda_{q p}=-\lambda_{\alpha p} \sin \left(\theta_{p}\right)+\lambda_{\beta p} \cos \left(\theta_{p}\right)
\end{array}\right\}
\end{aligned}
$$

Fig. 4 shows the block diagram of the $\alpha \beta / \mathrm{dq}$ transformation and a phase locked loop (PLL) used for power winding flux angle estimation. In resume, the PLL provides the power winding flux angle such that the d-axis is aligned with total power winding flux $\lambda_{\mathrm{p}}$, i.e., $\lambda_{\mathrm{dp}}=\lambda_{\mathrm{p}}$ and $\lambda_{\mathrm{qp}}=0$. In order to set the initial condition of integration block the constant $\omega_{\mathrm{e}}$ (angular grid frequency) is added after the PI controller [8].

The dynamic performance of the PLL during the startup of the system is shown in Fig. 5. This result shows that, at the startup system, the flux position operating point is reached in approximately $0.1 \mathrm{~s}$. This flux angle estimator strategy has demonstrated a good performance even in the presence of noise in the voltage and current acquisition. 


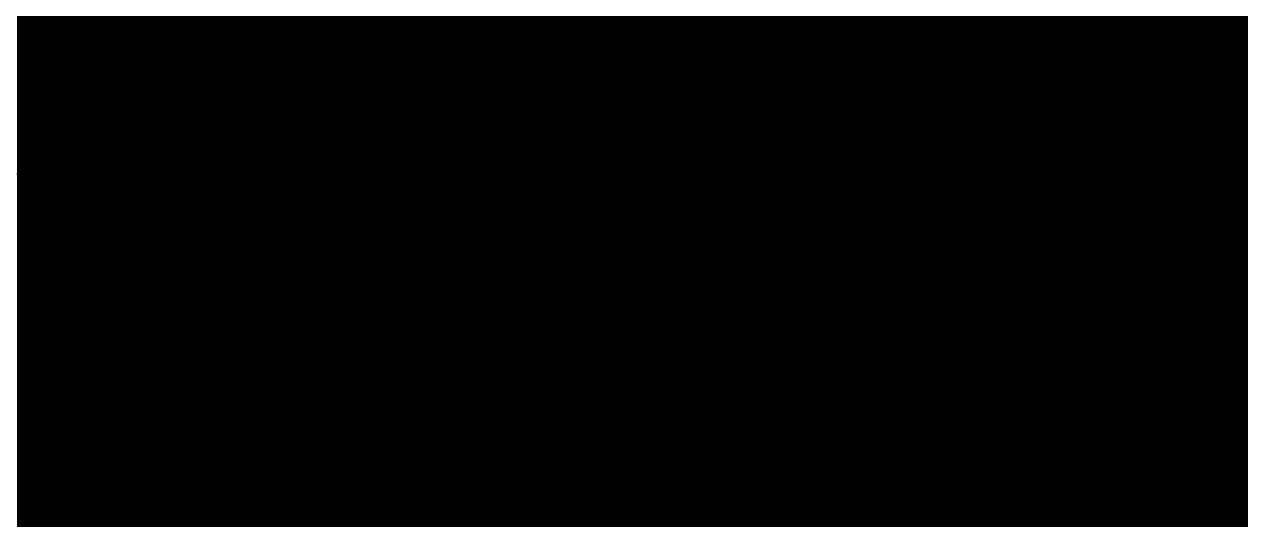

Fig. (4): PLL power winding flux angle estimation.

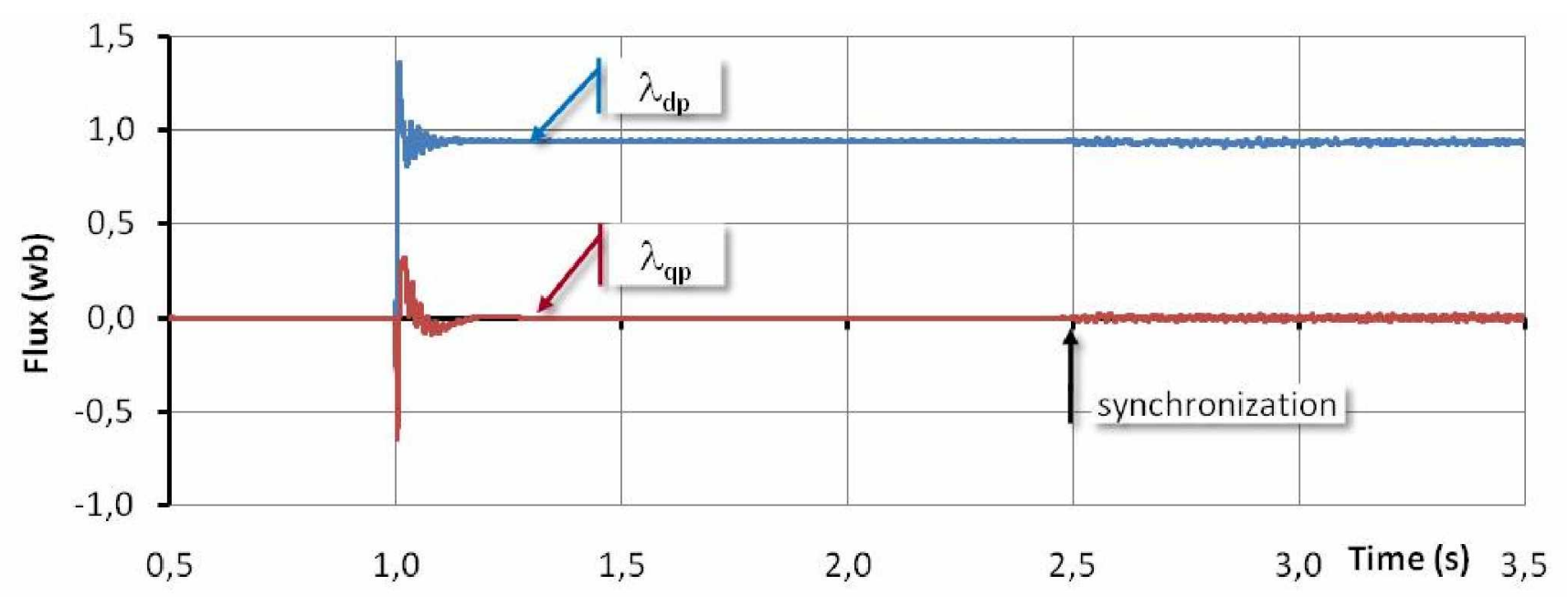

Fig. (5): Estimated dq power winding flux dynamics.

\section{Synchronization to the grid strategy:}

The grid connection is realized when the machine speed reaches the minimum operating value. A soft connection of the generator to the grid is obtained when the phase, frequency and amplitude of the power winding and grid voltages are equal before the switch S1 of Fig. 2 is closed.

The block diagram in Fig. 6 shows how the synchronization of the power winding and grid voltages algorithm was implemented.

To start synchronizing the generator with the grid, the control winding is fed by the back-to-back converters to create a power winding flux and induced voltages. The power winding voltages $\mathrm{V}_{\mathrm{abp}}^{\prime}, \mathrm{V}_{\text {cap }}^{\prime}$ and the grid voltages $\mathrm{V}_{\text {abp }}$ and $\mathrm{V}_{\text {cap }}$ are acquired using similar procedures. With the angle $\theta_{\mathrm{p}}$, obtained from the PLL, the transformation $\alpha \beta / \mathrm{dq}$ is applied to both grid and power winding voltages. The grid voltages $V_{d p}$ and $V_{q p}$ are 
compared to the power winding voltages $\mathrm{V}_{\mathrm{dp}}^{\prime}$ and $\mathrm{V}_{\mathrm{qp}}^{\prime}$. The resulting error is processed by the PI controller that acts over the control winding $i_{\mathrm{dc}}$ and $\mathrm{i}_{\mathrm{qc}}$ current control loops. As the angle used in the grid and power winding $\alpha \beta / \mathrm{dq}$ voltages transformation is the same, equal $V_{d p}$ and $V_{d p}^{\prime}$ values and equal $V_{q p}$ and $V_{q p}^{\prime}$ values imply equal phase, frequency and amplitude of the grid and power winding voltages. In other words, when the error signals of the dq grid and power winding voltages reaches a small defined value; the synchronism is attained and the system is ready for connection. At this moment a signal is sent by the software to turn on switch $\mathrm{S} 1$.

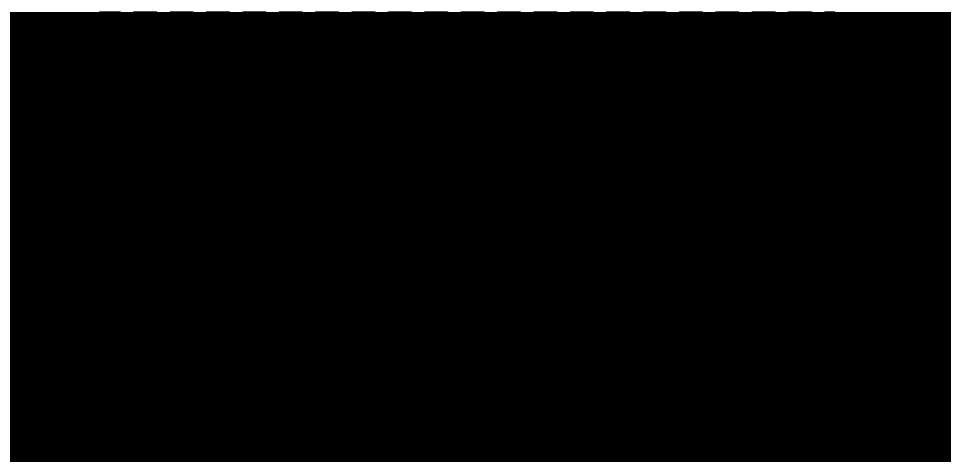

Fig. (6): Block diagram of the synchronization controller.

Fig. 7 shows the simulated results of a synchronization process, $\mathrm{t} 1$ and $\mathrm{t} 2$ define the initial and the final instants of the process, here they are $\mathrm{t} 1=2.38 \mathrm{~s}$ and $\mathrm{t} 2=2.45 \mathrm{~s}$.

The quality of the synchronization procedure can be evaluated examining the phase ' $a$ ' currents in both the power and the control windings presented in Fig. 8. No severe transient is observed on those currents.

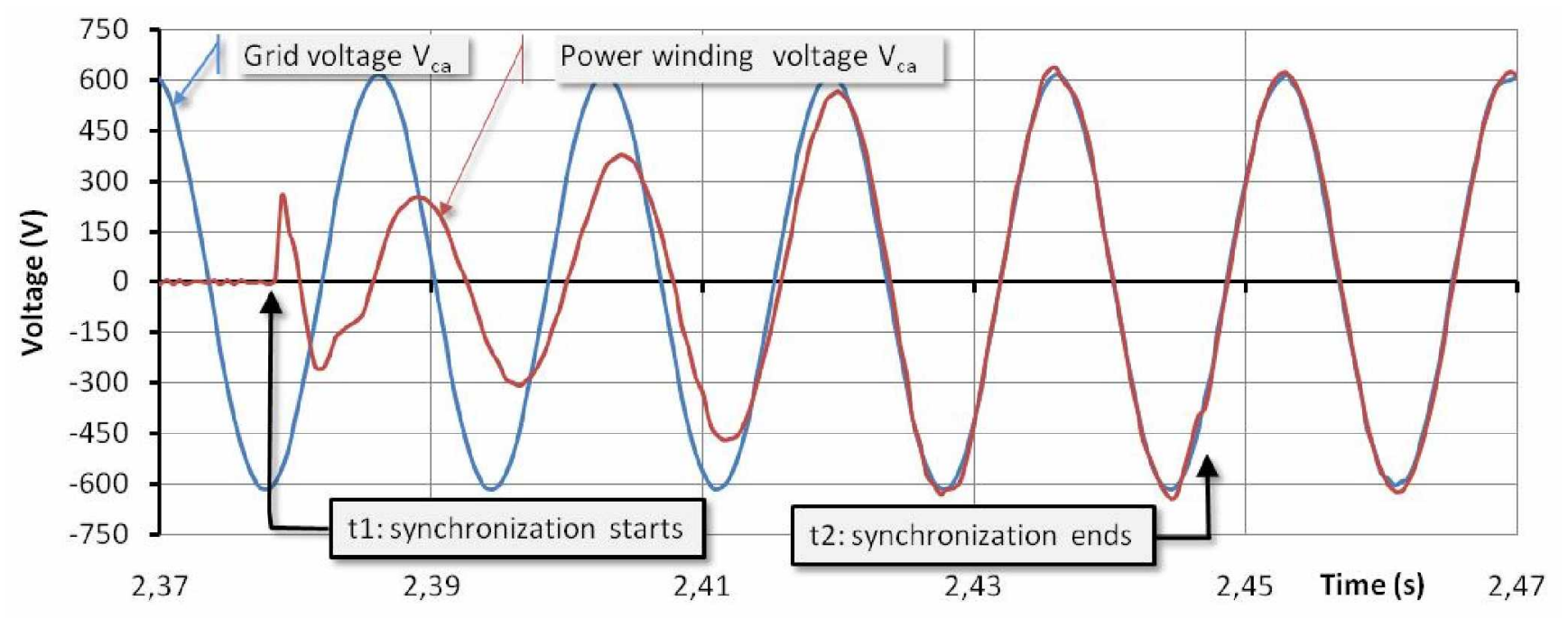

Fig. (7): Simulated results: power winding and grid voltages during the synchronization 
process.

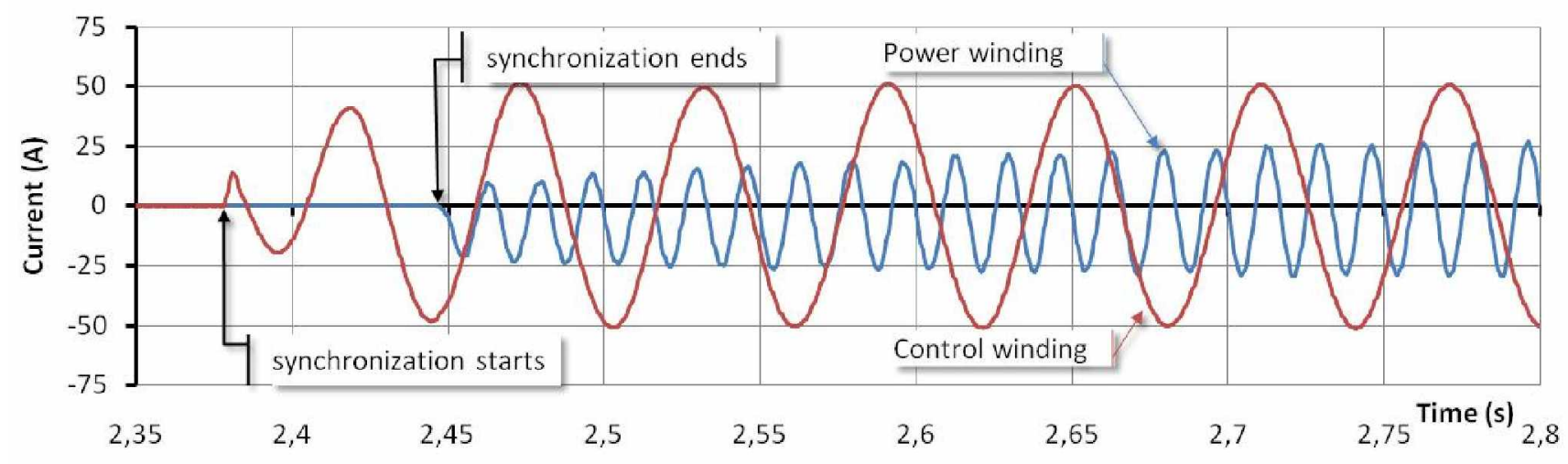

Fig. (8): Simulated results: Power and control winding phase ' $a$ ' currents during the synchronization process.

\section{Experimental results on a DFIG system:}

In order to verify the control and synchronization strategy here proposed, an experimental bench based on a wound rotor induction machine was set-up. The same strategy and components were used in this test bench.

Fig. (9) shows the grid and stator voltages during the synchronization process as well as the rotor currents.

Fig. (9): Experimental results of a DFIG - stator and grid voltages, $i_{r a}$ and $i_{r b}$ rotor currents during the synchronization process. 
The experimental dq voltages of Fig. 9 are shown in Fig. 10 during the synchronization process. In this figure, $\mathrm{t} 1$ corresponds to the start of the synchronization procedure. At time $\mathrm{t} 2$ the grid side and the stator side voltages amplitude, phase and frequency are sufficiently close and the order is given to switch S1 to close. However, there is a time delay between the instant the order to close is send (t2) and the instant the switch is effectively closed ( $\mathrm{t} 3)$.

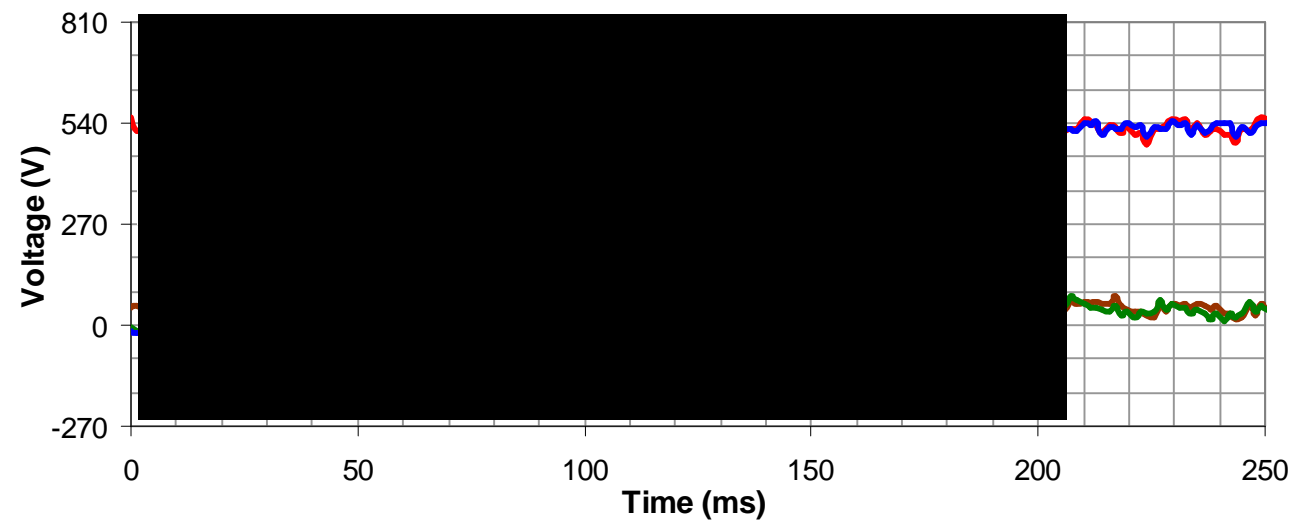

Fig. (10): Experimental $d q$ grid and stator voltages of a DFIG during the synchronization process.

\section{Conclusions:}

In this paper the vector control of the BDFIG using a rotating reference frame fixed on the power winding flux was implemented in Matlab/Simulink/SymPowerSystems. The simulations of the PLL in order to measure the power winding flux angle show good performance during the system startup and its implementation on an experimental DFIG setup has demonstrated a robust behavior under noisy voltage and current signals.

The proposed synchronization process showed to be fast and smooth. Matching the amplitude, frequency and phase of the power windings and grid voltages it assures the conditions for the connection by acting over the control windings current control loops.

\section{References:}

[1] R. Pena, J.C. Clare, G.M Asher, "Doubly fed induction generator using back-toback PWM converter and its application to variable-Speed wind-energy generation.” IEE Proc.-Electr. Power Appl., Vol. 143, No. 3, May 1996.

[2] H. Voltolini, R. Carlson, F. Runcos, N. Sadowskim P. Kuo-Peng, "Performance and Vibration Analysis of a $75 \mathrm{~kW}$ Brushless Double-Fed Induction Generator Prototype.” IEEE/IAS 41st Annual Meeting, Florida, EUA, October 8 - 12, 2006. 
[3] R. Carlson, H. Voltolini, F. Runcos, P. Kuo-Peng, “A performance Comparison Between Brush and Brushless Doubly FED Asynchronous Generators for Wind Power Systems." International Conference on Renewable Energies and Power Quality - Palma de Mallorca/Espanha, v.1, p. 1-5, 2006.

[4] Y. Tang and L. Xu, "Flexible active and reactive power control strategy for a variable speed constant frequency generating system," IEEE Trans. Power Electron., vol. 10, no. 4, pp. 472-478, Jul. 1995.

[5] S. Peresada, A. Tilli, A. Tonielli, "Indirect stator flux-oriented output feedback control of a doubly fed induction machina", IEEE Transactions on Control Systems Technology, vol. 11, no. 6, pp. 875-888, November 2003.

[6] G. Yuan; J. Chai; Y. Li, "Vector control and synchronization of doubly fed induction wind generator system”, IPEMC 2004, Volume 2, 14-16 Aug. 2004 pp. 886 - 890. August 14-16, 2004, Xi'an, China.

[7] A.G. Abo-Khalil, D-C Lee, S-H Lee, "Grid connection of doubly-fed induction generators in wind energy conversion system", IPEMC 2006, Vol. 3, 14-16 Aug. 2006, pp. 1 - 5. August 14-16, 2006, Xi'an, China.

[8] V. Kaura, V. Blasko, "Operation of a Phase Locked Loop System under distorted Utility Conditions", IEEE Transactions on Industry Applications, Vol. 33, n. 1, pp. 58-63, January/February 1997.

\section{Nomenclatures:}

$\theta_{\mathrm{e}} \ldots$ Grid voltage space vector position

$\theta_{\mathrm{p}} \ldots$ Power winding flux position

$\lambda_{\mathrm{s}} \ldots$ Power winding vector space flux

$\lambda_{\mathrm{qp}} \ldots$ q-axis power winding flux

$\lambda_{\mathrm{dp}} \ldots \mathrm{d}$-axis power winding flux

$\omega_{\mathrm{r}} \ldots$ Rotor speed

$\mathrm{P}_{\mathrm{e}} \ldots$ Grid active power

$\mathrm{Q}_{\mathrm{e}} \ldots$ Grid reactive power

$\mathrm{v}_{\mathrm{qe}} \ldots$ q-axis grid voltage

$\mathrm{v}_{\mathrm{de}} \ldots \mathrm{d}$-axis grid voltage

$\mathrm{i}_{\mathrm{qe}} \ldots \quad$ q-axis grid current

$i_{\text {de }} \ldots$ d-axis grid current

L... Grid converter line choke inductance

R... Grid converter line choke resistance

$\mathrm{V}_{\mathrm{q} 1} \ldots$ q-axis AC-side grid converter voltage

$\mathrm{V}_{\mathrm{d} 1} \ldots \mathrm{d}$-axis AC-side grid converter voltage

$\mathrm{V}_{\mathrm{e}} \ldots$ Grid voltage space vector 